\title{
ON THE ISSUE OF ENVIRONMENTAL FEASIBILITY OF WATER SUPPLY INTENSITY C USING LOW- VOLUME IRRIGATION TECHNOLOGY. (IN THE EXAMPLE OF THE GUBINSKY RACN)
}

\author{
Prof. Dr. Z.H. Aliev
}

Email: zakirakademik@mail.ru

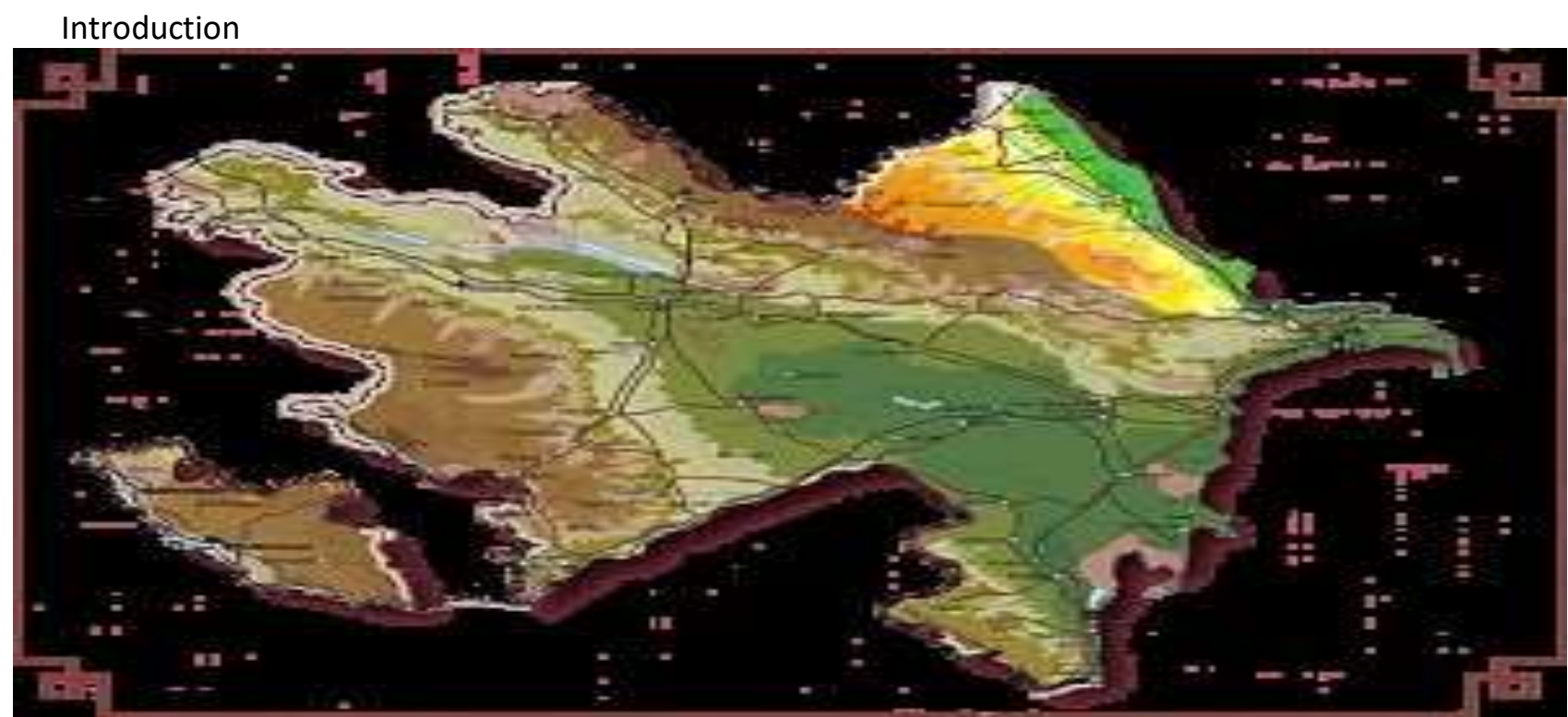

Recently, the Government of the Republic of Azerbaijan has been paying considerable attention to the development of one of the main factors in the intensification of agriculture, irrigation reclamation.

The long-term program for its development provides as an extension of the state of existing irrigation systems. One of the promising areas in Azerbaijan for the cultivation of vegetables, fruits, etc. is the Guba-Khachmas zone, where in recent years numerous specialized farming and individual farms for the production of fruits and vegetables have been organized.

At present, in the Guba-Khachmas region, irrigation using the furrow method and in places with built-in stationary pulsed sprinkler devices of self-oscillating action (SIMDAD) from a closed network is used in the Guba-Khachmas zone for irrigation of vegetables and fruit trees.

The use of irrigation methods existing in this region (furrow irrigation and or conventional irrigation) under the conditions under consideration often leads to soil erosion.

One of the ways to increase the efficiency of stationary sprinkler systems on steep slopes is the introduction of technology and technical means of lowintensity irrigation, which could reduce construction costs and completely eliminate soil erosion.

For this purpose, it is necessary to apply appropriate ecologically acceptable equipment, which should provide the following multi-intensive long-term impact on the plant, soil and surface air layer by reducing the intensity of water supply (I) 
and bringing its value closer to the intensity of water consumption (E).

$$
\text { And } \leq(\mathrm{I}-100) \mathrm{E} \text {; }
$$

To the foregoing, synchronous sprinkling is most suitable.

Pulse sprinkling systems operate in a semiautomatic mode and during continuous operation the daily water supply is $96 \mathrm{~m} 3$ / ha, which is almost three times higher than the average daily water consumption rate of an agricultural field in this zone.

Along with other regions of the republic in the conditions of the Guba and Khachmas districts under the leadership of Prof. B.G. Aliyev, employees of the Research Institute "Erosion and Irrigation" in the period 2005-2007 targeted research was conducted using pulsed sprinkling of self-oscillating action. It was found that the frequency of irrigation and the intensity of water supply affect the productivity of the use of natural rainfall. Fig. one.

Throughout all studies conducted in the period 2005-2007 At the production facilities of the Cuban Regional Agrarian Center of Science (RACS), the Ministry of Agriculture supplied water by evaporation taking into account productively used precipitation, and in the control variant, the calculated irrigation rate for the lower threshold of soil moisture was $80 \%$ PPV.

In this regard, the self-oscillating pulsed irrigation systems (hereinafter SIDAD), introduced on an area of 2.8 hectares, make it possible to provide water supply to the irrigated area up to $96 \mathrm{~m} 3$ / ha.

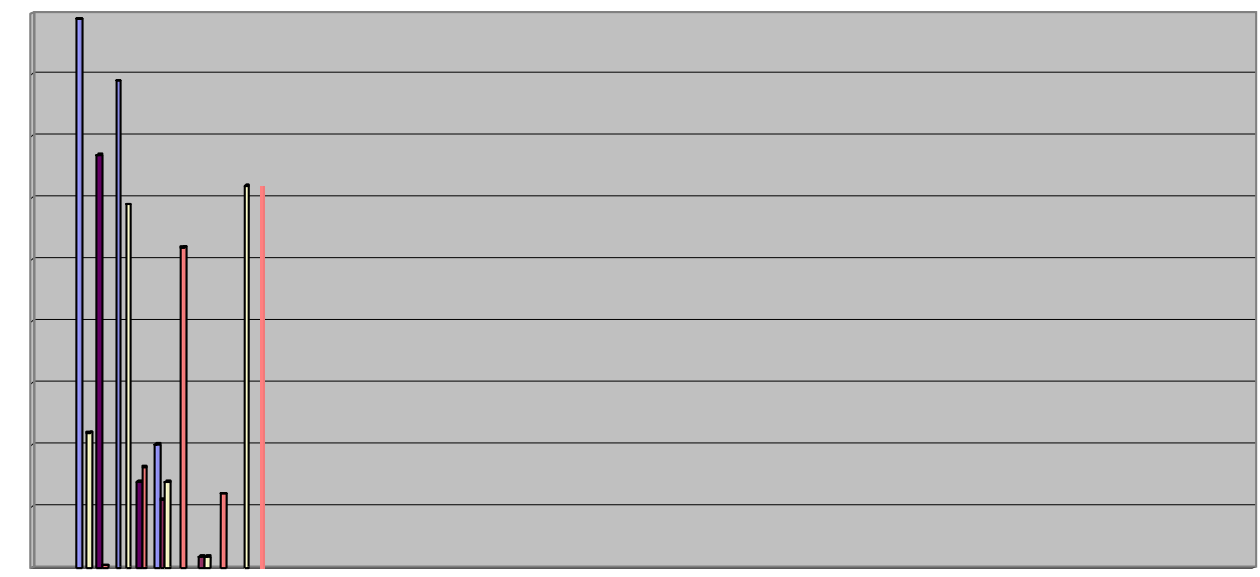

Fig. 1. Precipitation during the growing season of 2005

Fig. 2. Precipitation during the growing season of 2006 
In this case, we used the density and PPV determined by us, which are respectively equal: $2005-\square=1.45, \beta=32 \% ; 2006-\square=$ $1.45, \beta=32 \% ; 2007-\square=1.45, \beta=32 \%$.

The experimental curve of the coefficient of utilization of precipitation $\mathrm{K}$ with $\mathrm{a}$ reliability of $0.98 \%$ is described with pulse sprinkling by the formula:

$K=e-0.014 \times(h-6)$

during normal sprinkling:

$K=e-0.047 \times(h-6)$

The data obtained are approximated by a curve true for heavy loamy soil and average rainfall intensity in the study area.

We found that the intensity of water supply during the study period exceeded the intensity of water consumption. On the option of round-the-clock irrigation, the coefficient of excess of the intensity of water supply over water consumption is 0.72-0.80, with normal sprinkling - 0.99 . Under the conditions under consideration, the total evaporation with a security of $95 \%$ is $38 \mathrm{~m} 3 /$ ha day.

In fig. 4. graphs of average evaporation are presented for the experimental options for April - September 2005-2007.

$\mathrm{Mm}$

Fig. 4. The average daily evaporation in 2005-2007

Table 1

Indices of irrigation regime during the vegetation period of plants

Options Years Atmospheric precipitation, $\mathrm{mm}$ Productively used precipitation, $\mathrm{mm}$ Number of irrigations Irrigation rate, m3 / ha

Micro-sprinkling irrigation of self-oscillating action (IMDAD) 2005383272731570

2006359215922130

20071981391221630

Furrow irrigation 200538317753712

200635911264887

20071987464253
This method has become more widespread regulation of the water regime of the soil. With traditional methods of irrigation, reaching critical parameters of soil moisture (65\% PPV.) Is a signal to start watering. Continue it until the soil is completely saturated, i.e. up to $100 \%$ PPV. The consequence of this is that in the pre-irrigation period, plants suffer from a water shortage, and at the end of watering and for some time after it, they lack soil air. Irrigation systems with sprinkling (SIDAD) allow irrigation with significant fluctuations in the water balance of the soil. Using strain gauge posts, an evaporometer and simple calculations, it is possible to keep the soil moisture fluctuation within $75-85 \%$ of $\mathrm{HB}$. This means that the range of these variations is 3-3.5 times less than with traditional irrigation. With the help of the sprinkling irrigation system and the agrotechnical potential that this system brings to practice, it is possible not only to maintain soil moisture at an optimal level, but also to artificially lower it into certain phenophases of plant development.

Lowering the soil moisture in the garden during flowering increases the percentage of productive ovary. A more intense water regime during the differentiation of fruit kidneys also, according to some researchers, contributes to an increase in the number of generative kidneys.

During the irrigation period, on options for micro-sprinkling, the deviation of soil moisture from the required level $190 \%$ of the WSP) was due to meteorological factors. In fig. expressed that using IDAD soil moisture can be maintained at the required level. The exception is the months when the rainy period comes.

Between April and September, the rains fell relatively unevenly and in small quantities.

In certain periods of the irrigation season, soil moisture stabilized at the required level. The obtained data on soil moisture are given in table 2-5. 
Thus, micro-sprinkling with the use of SIDAD allows maintaining soil moisture at a given level, which has a beneficial effect on growth processes and crop formation.

In the formation of agricultural crops, the microclimatic effect created by microsprinkling is also of great importance.

Irrigation causes a change in the heat exchange of the soil with air in the direction of its decrease. Changes in heat transfer under the influence of irrigation are associated with a change in the microclimatic regime in the surface soil layer, which in turn affects the growth and development of plants. So, for example, plants may lack moisture in high soil moisture. The duration of the effect of irrigation by sprinkling on the microclimate of the surface air layer depends on climatic conditions, the size of the irrigated area, and also the irrigation technique and technology.

table 2

Soil moisture on the test options, in\% of the weight of a.s.p. 2005 year

Options $08.420 .4 \quad 03.523 .5 \quad 15.6 \quad 02.725 .7$ 19.828 .814 .9

Micro-sprinkling using a self-oscillating $\begin{array}{llllll}\text { apparatus } 23.1 & 24.0 & 27.2 & 26.1 & 25.8 & 26.0\end{array}$ 26.425 .926 .325 .5

Furrow irrigation 23.1 24.029 .028 .025 .4 29.025 .822 .629 .530 .0

\section{Table 3}

Soil moisture on the test options, in\% of the weight of a.s.p. 2006

Options 26.501 .611 .626 .611 .0620 .728 .7 01.810 .818 .824 .8

Micro sprinkling using a self-oscillating apparatus 24.5

27.0

26.9

27,2

26.8

27.0

26.9

27.0

27.1

27.026 .5
Furrow irrigation 24.5

28.9

23.8

29.1

24.4

28.7

23.9

29.5

23,2

28.624 .0

Table 4

Soil moisture on the test options, in\% of the weight of a.s.p. 2007 year

Options 01.415 .424 .410 .523 .506 .620 .6 08.720 .730 .715 .8

Micro-sprinkling using a self-oscillating apparatus $\begin{array}{llllll}25.0 & 26.0 & 27.5 & 25.4 & 25.2 & 27.3\end{array}$ 26.328 .527 .225 .626 .4

Furrow irrigation 25.0

27,2

24.8

28.624 .529 .0

24.429 .624 .829 .125 .0

By 15-16 hours, the air temperature in the micro-sprinkling variant was $4-5^{\circ} \mathrm{C}$ lower.

Humidity in the case of pulsed sprinkling throughout the day was higher than with furrow irrigation.

The greatest gradient of air humidity between the options was observed after 10 hours, it reached $10-20 \%$ at a height of $0.6 \mathrm{~m}$.

In figures 5-7. The results of measurements of microclimate parameters in the daytime are presented.

At 12-13 o'clock in the afternoon, the air temperature over a height of $1.6 \mathrm{~m}$ was 70-90 ${ }^{\circ} \mathrm{C}$ higher with the furrow irrigation variant than with the micro-sprinkler variant. This irrigation technology allows you to significantly affect the plants and their habitat almost throughout the growing season, with the exception of rainy or cloudy periods, when the natural humidity is high and the soil is sufficiently provided with moisture. In this case, watering is no longer necessary. 
Fig. 5 Dynamics of soil moisture under various irrigation options, 2007

Comparison of these measurements with measurements performed with an hourly interval shows their mutual characteristic. Micro-sprinkling allows in the hot hours of the day, by increasing the relative humidity by $10-20 \%$, to reduce the temperature by $1.5-2.50 \mathrm{C}$. Analyzing the foregoing, it is possible with to conclude that micro-sprinkling during the entire irrigation period increases air humidity and reduces its temperature in the daytime. Studying the effect of the longterm effects of sprinkling and microclimate on the growth and development of fruit trees is one of the objectives of our research.

Table 5

Microclimatic indicators over the apple tree

(average indicators in 2005-2007)

Duration

days, hour

Options 810121416182022

Micro-sprinkling with the use of a selfoscillating apparatus 16.519 .826 .418 .6

65605563

Furrow irrigation 16.522 .63120 .4

\section{6}

This irrigation technology allows you to significantly affect the plants and their habitat almost throughout the growing season, with the exception of the rainy season.

Fig. 6. Change in the dynamics of air temperature above the apple tree with various irrigation options.

Fig. 7. Change in the dynamics of air humidity over the apple tree with various irrigation options.

In the design and operation of pulsed sprinkling systems, an important element is the determination of its technological parameters.

We theoretically calculated technological parameters with optimal water supply. pulse micro-sprinkling in the study area (96m3 / ha day., 48m3 / ha day., 32m3 / ha day.). Moreover, compared with the existing water supply $96 \mathrm{~m} 3$ / ha day. The technological parameters of pulsed sprinkling of self-oscillating action are changing for the better, where the specific water supply is 0.62 I / s.ha., The flow rate supplied to one device is 0.031 I / s., The accumulation duration is $483 \mathrm{~s}$., The average circular intensity is 0.0037 $\mathrm{mm} / \mathrm{mm}$, watering efficiency coefficient 0.67 (tab. 6).

Technological parameters of selfoscillating pulsed micro-sprinkling systems

Table 6

№№

$\mathrm{p} / \mathrm{p}$

Indicators

Symbol

unit of measurement

Settlement formula or set parameters

Average daily water supply, m3 / ha

96

48

32

\section{8}

1 Upper pressure limit in the hydraulic accumulator PV MPa According to the operating characteristic of the pump 0.45 0.450 .45

2 The geometric volume of the hydraulic accumulator $\mathrm{Vg}$ I Design and construction 303030

3 The angle of rotation on the duty cycle $\varphi$ Grad. structurally 151515

4 Lower pressure limit in the hydraulic accumulator PH MPa (0.39) Pv 0.3 0.3 0.3 5 Water discharge per working cycle Vout I V-Pd [(Pv) 0.9] 
Rv Rn 151515

6 Radius of action $\mathrm{R} m$ experimentally 22 2222

7 Irrigation area when placed according to the triangular pattern $\omega 0$ ha $10-42 R 2$ $0,0970,0970,097$

8 Specific water supply q / I / sec. 2 d - 1, 040.620 .36

9 Consumption supplied to one apparatus qd I / s w0q 0.0620 .0310 .025

10 Duration of accumulation Tn sec Vsign ad 240483600

11 Duration of emission Tws sec Vsubs

12 Cycle time T s TH + Tb 261512640

13 Average circular intensity $\rho \mathrm{mm} / \mathrm{min}$ 6.10-3 q 0.00620 .00370 .0021

14 Number of duty cycles per revolution $n$ 242424

15 Irrigation efficiency coefficient 0.67 0.670 .67

16 Insufficient watering coefficient 0.18 0.180 .18

17 Over-watering coefficient $0.15 \quad 0.15$ 0.15

The disadvantage of the option with an average daily water supply of $96 \mathrm{~m} 3$ / ha is that in a relatively short time (within 10 hours) the daily irrigation rate is provided, and the inter-irrigation period lasts 14-16 hours. At the same time, the microclimatic effect of irrigation worsens, and the utilization rate of equipment decreases.

In addition, technically, there is a deterioration in the conditions of normal operation of the system due to the filling of pipelines with air during interruptions in water supply, corrosion processes intensify.

The above data indicate the economic feasibility of using synchronous pulsed sprinkling in the conditions under consideration.

The introduction of automated systems of pulsed micro-sprinkling in the foothill regions of the republic allows preserving the fertility of the earth, protecting the soil from irrigation erosion, and increasing plant productivity. All this is one of the ways to implement decisions to further intensify agricultural production, which is especially important for mining in the republic.

\section{Literary sources}

1. B.G. Aliev ZG Aliyev - Technique and technology of low-intensity irrigation in the conditions of the mountainous region of Azerbaijan Elm Publishing House Baku 1999220 p.

2. B. G. Aliev, Z. G. Aliyev - Irrigated agriculture in the mountainous and foothill regions of Azerbaijan. Publishing House "Ziyaya-Nurlan". Baku 2005, 330 p.

3. Aliyev B.G., Aliev I.N.- Some problems of agriculture in Azerbaijan and ways to solve them Ziyaya-Nurlan Publishing House. Baku 2004, 572p. (Azeri Language)

4. International Center for Agricultural Research in arid and arid regions (ICARDA) Irrigation regime and monitoring technique. Edited by $U$. Umarov and A. Karimov C. Taraz: IC "AQUA", 2002, $128 \mathrm{~s}$.

5. V.F. Nosenko Irrigation in the mountains. Kolos Publishing House Moscow 1981143 p.

6. Yu.A. Markov Irrigation of collective and household gardens of the agricultural organization Agropromizdat Leningrad $198964 \mathrm{p}$. 